\title{
DIREITOS HUMANOS E MEIO AMBIENTE: IMPLICAÇÕES PARA A SUSTENTABILIDADE
}

\author{
HUMAN RIGHTS AND THE ENVIRONMENT: \\ IMPLICATIONS FOR SUSTAINABILITY
}

\author{
CLEITON LIXIESKI SELL \\ ACADÊMICO do CURSO dE DIREITO dA UNIVERSIDADE DE CRUZ ALTA - UNICRUZ \\ cleitonls.direito@gmail.com
}

DANIEL RUBENS CENSI

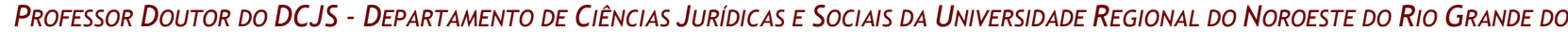
SUl - UNIJUII, COORDENAdOR dO PROJETO de PESQUISA “O DIREITO AMBIENTAL NO CONTEXTO DA SOCIEDADE DE RISCO: EM BUSCA DA JUSTIÇA AMBIENTAL E DA SUSTENTABILIDADE". danielr@unijui.edu.br

FÁTIMA BARASUOL HAMMARSTRÖN Mestre em Desenvolvimento pela Universidade Regional do Noroeste do Rio Grande do Sul - UNIJUÍ; pesquisadora da CAPES; membro do grupo de Pesquisa "O direito ambiental no contexto da sociedade de risco: em busca da justiça ambiental e da sustentabilidade" ; Docente da Graduação e Pós Graduação da Universidade de Cruz Alta - UNICRUZ.

\section{RESUMO}

A sustentabilidade de forma geral se apresenta como uma espectativa universal de desenvolvimento econômico dos individuos que convivem em uma sociedade onde valores educacionais morais são esquecidos. 0 método dedutivo trabalhado no texto encontra suporte nas leituras e abordagens de autores sobre o tema em questão. Contudo, o sonho de um planeta mais sustentável se converte em um campo onde traçam-se uma série de disputas socioeconômicas bem como, espaciais, dentro de um desafio da própria economia. Um olhar interdisciplinar e crítico sobre o direito de um ambiente mais sustentável revela processos crescentes de desrespeito aos direitos humanos, pela sonegação do acesso ao meio ambiente ecologicamente equilibrado. Para tal, o direito ao ambiente torna-se um requisito essencial para a qualidade de vida e cidadania, onde seu enfrentamento requer maiores investimentos $e$ processos de planejamento de gestão para garantir o acesso aos bens fundamentais do ser humano.

Palavras-chave: Direitos humanos; Meio ambiente; Meio Ambiente Urbano; Sustentabilidade.

\begin{abstract}
Sustainability generally presents itself as a universal expectation of economic development of the individuals who live in a society where moral educational values are forgotten. The deductive method worked in the text finds support in the readings and approaches of authors on the subject in question. However, the dream of a more sustainable planet becomes a field where trace a series of disputes as well as socioeconomic, spatial, within the very challenging economy. An interdisciplinary and critical eye on the right to a more sustainable environment reveals growing processes of human rights abuses, by withholding access to an ecologically balanced environment. To this end, the right to environment becomes an essential requirement for quality of life and citizenship, where his coping requires greater investment and management planning processes to ensure access to basic necessities of human beings.
\end{abstract}

Keywords: Human rights; Environment; Urban Environment; Sustainability. 


\section{SUMÁRIO}

INTRODUÇAO; 1. DESENVOLVIMENTO SUSTENTÁVEL: POR UMA GESTÃO AMBIENTAL DEMOCRÁTICA SOB OS OLHOS DO DIREITO AMBIENTAL; 2. OS DIREITOS HUMANOS E A EFETIVAÇÃO PARA UM MEIO AMBIENTE SAUDÁVEL: UM DASAFIO PARA SOCIEDADE CONTEMPORÂNEA; 3. JUSTIÇA AMBIENTAL E $O$ CIDADÃO: A SUSTENTABILIDADE INDISSOCIÁVEL DA DEMOCRACIA E DO HUMANISMO; 4. CONCLUSÃO; 5. REFERÊNCIAS.

\section{INTRODUÇÃO}

Hodiernamente, a relação da humanidade com a natureza dá-se desde os tempos mais remotos em que exite no homem o figura de um ser dominante do meio ambiente em que está situado. No entanto o interesse do mercado por sua vez, é que dá irracionalidade à forma como elas têm se organizado, pois os cidadãos em conjunto com o Estado, são os agentes ativos que podem tentar diminuir eventuais ações impactantes ao meio ambiente, ao ecossistema que o sustenta e, por conseguinte garantir uma melhor qualidade de vida para si e para as futuras gerações.

O presente trabalho foi desenvolvido através de revisão bibliográfica, tendo como indicativo o dedutivo, também denominado como hipotético por alguns autores. 0 alicerce neste método ainda constitui-se de leituras e fichamentos de autores que abordam o tema discutido, construindo-se hipóteses que foram confrontadas com fatos obtidos pelas leituras.

Para tal abordagem, o texto foi dividido em um primeiro momento na importância da gestão ambiental para o desenvolvimento sustentável, onde discorre sobre a dificuldade para sua implantação, uma vez que, envolve a participação dos cidadãos e a estrutura do governo. Em um segundo momento, foi avaliada a efetivação do direito ao meio ambiente frente a atual crise social ambiental onde está inserida a diversidade de valores. Por fim, são abordadas questões da democracia, cidadania e justiça ambiental, trazidas como um caminho no rumo do meio ambiente ecologicamente equilibrado. Esse crescimento da cultura de um desenvolvimento sustentável sob a ótica positivista, somente vem a ser inserida no momento em que 
surgem normas específicas que limitam à ação antrópica do ser humano no meio ambiente.

\section{DESENVOLVIMENTO SUSTENTÁVEL: POR UMA GESTÃO AMBIENTAL DEMOCRÁTICA SOB OS OLHOS DO DIREITO AMBIENTAL}

Como mostra a atual conjuntura da sociedade, o processo crescente e desordenado de destruição do meio ambiente foi lento e está tomando forma assustadora. No entanto, nos últimos 50 anos por exemplo, verificam-se não só as maiores taxas como também o alastramento do fenômeno em todo o território. Segundo dados apresentados por Menegat e Almeida ${ }^{1}$, enquanto em 1950 a população urbana correspondia a 36\% da população total, no início dos anos de 1970 esse percentual saltou para 56\%. Em 1980 os cidadãos urbanos já representavam 67\% da população total e, no início da década de 1990 foi de $75 \%$.

Devido a esse fator, a desigualdade social no mundo como um todo também tomou proporções assombrosas. Entretanto, os setores populacionais mais pobres foram os que mais cresceram em comparação aos mais ricos. Um exemplo explícito dessa divergência está nas cidades informais, ou melhor, que não tiveram um urbanização correta, vindo a proliferar com taxas muito maiores do que em relação às cidades formais.

Um dos fatores relevantes que levam o conceito de proteção ambiental não ser visto com olhos os que deveriam, se deve ao fato do próprio sistema político-administrativo não impulcionar soluções que hora se faze necessárias para que se tenha resultados concretos. Diante do exposto, caminha-se a passos largos em um caos que trará os mais pesados efeitos que vão atingir em níveis diferentes a todos os indivíduos.

No entanto o crescimento dessa crise associado ao aumento de encargos e serviços dos governos locais, à carência de recursos financeiros e à falta de planejamento e gestão ambiental, têm levado o meio ambiente, e o ser humano a situação de desagregação social. Tal fato resta comprovado em ocupações irregulares próximo a centros urbanos.

Um aspecto a ser observado, e que está diretamente relacionado, é a gestão pública, pois, devem ser adotadas medidas que estejam pautadas em um planejamento progressivo das

\footnotetext{
1 MENEGAT, Rualdo; ALMEIDA, Gerson. Sustentabilidade, Democracia e Gestão Ambiental Urbana. In: MENEGAT, Rualdo; ALMEIDA, Gerson (Orgs.). Desenvolvimento Sustentável e Gestão Ambiental nas Cidades - Estratégias a partir de Porto Alegre. Porto Alegre: Editora da UFRGS, 2004, p. 296.
} 
ações, pois, na maioria das vezes, as próprias questões burocráticas centralizam a execução propriamente dita das atividades. Ao pressupor o planejamento como atributo exclusivamente técnico, desconsidera o papel do cidadão na tomada de decisões e na implantação de programas que visem ampliar a proteção ambiental sob uma perspectiva local e depois mundial.

Em regra os governos locais consideram apenas os problemas existentes locais, ignorando que estas possuem um vínculo com os ecossistemas do seu entorno, que é próprio do crescimento economico de uma região, vindo a eliminar a natureza remanescente em seu território. Essa desconsideração do planejamento se dá por vez, pelas pressões sofridas em busca de um crescimento social-economico imediato.

Somado-se a essas questões, tem-se a visão patrimonialista de grande parte dos partidos políticos que assumem os governos locais. A falta de transparência e a corrupção são constantes da gestão pública. Nesse contexto, vale lembrar que o imediatismo, tanto da violência como também da pobreza, são vistos como pertencentes à própria natureza regional do planeta.

Para se alcançar o caminho traçado em direção ao objetivo que gira em torno da sustentabilidade, a ação será distinta para cada localidade, pois, como se trata de um problema mundial, terá soluções e resultados de diferentes proporções. Mas a solidariedade, a democracia participativa, o entendimento e a negociação entre os setores sociais, a construção do conhecimento e a interação com o sistema natural podem ajudar a visualizar os contextos específicos de cada localidade 2 .

Complementando, com esse raciocínio, Menegat afirma que a democracia participativa “não pode ser um processo sem lugar, sem cara e sem cultura popular, que é preciso desenvolvê-lo, inventá-lo a cada momento, porque ele é promotor da identidade local, sem a qual, não há cidadania, isto é, a qualidade dos cidadãos e cidadãs"”.

O desenvolvimento sustentável de uma gestão de forma integrada é condição imperativa para o gerenciamento do sistema urbano-socioambiental em termos de sustentabilidade. Ainda colaborando, sintetiza Menegat que, “não há como tomar decisão sobre o lugar em que vivemos sem que cada um que decida tenha conhecimento do lugar em que vive, sem que possamos construir nossa identidade cultural em respeito ao lugar"”.

\footnotetext{
${ }^{2}$ MENEGAT e ALMEIDA, Op. Cit.

3 MENEGAT, Rualdo. Ciência Cidadã: democracia, e territorialidade por uma epistemologia urbana. In: MENEGAT, Rualdo; ALMEIDA, Gerson (Orgs.). Desenvolvimento Sustentável e Gestão Ambiental nas Cidades - Estratégias a partir de Porto Alegre. Porto Alegre: Editora da UFRGS, 2004. p. 298.

${ }^{4}$ MENEGAT, 2004, Op. Cit., p. 297.
} 
Diante desse cenário assustador projetado na visão ambientalista, que até pouco tempo praticamente resumia-se a apontar a necessidade da preservação de grandes ecossistemas, evoluiu principalmente a ideia de desenvolvimento sustentável. Com esse novo aspecto, nasce um percurso a ser seguido pela humanidade para acomodar o crescimento populacional e o incremento de demandas por bens materiais e matérias-primas. Essa nova mentalidade gerou vários movimentos, onde cabe destacar a ECO-92, que propôs o conceito de desenvolvimento sustentável, a Agenda 21 destacando o meio ambiente e desenvolvimento, bem como, a RIO+20, realizada na cidade do Rio de Janeiro em 2012.

O tema sustentabilidade é indissociável da democracia e do humanismo. Os compromissos de sustentabilidade implicam na adoção de mecanismos de participação que envolva amplos setores da população. Esses mecanismos não devem resumir a consultas, mas sim que tenham poder para incidir sobre a gestão governamental e a formulação de políticas públicas, onde através disso aumentará a democracia e a descentralização do poder e da organicidade social. Exemplificando, “construir estratégias de um futuro comum implica mudanças mais profundas do que meramente desenhá-las em um papel ${ }^{5 "}$.

Em se tratando de uma estratégia sustentável, deve implicar um fortalecimento da sociedade democrática e vice-versa. Entretanto, “isso quer dizer que mudou não só a capacidade da humanidade em transformar a natureza, mas fundamentalmente os mecanismos que vêm possibilitando tais transformações ${ }^{6 ”}$. Dessa forma, traça-se o ser humano como um fio condutor central, onde se utiliza da própria capacidade física e mental para dispor alterações no todo planeta.

\section{OS DIREITOS HUMANOS COMO UM ELO PARA UM MEIO AMBIENTE SAUDÁVEL: UM DASAFIO PARA SOCIEDADE CONTEMPORÂNEA}

0 surgimento do pensamento a respeito dos direitos humanos vem reagindo as preocupações com a sustentabilidade e com o cenário atual que se encontra o planeta terra. 0 desenvolvimento sustentável mais precisamente, foi o reconhecimento crescente da necessidade e da existência de um direito dos seres humanos a um meio ambiente limpo e saudável. Tem-se então, o direito ao meio ambiente equilibrado como uma das prerrogativas da quarta geração

\footnotetext{
${ }^{5}$ MENEGAT e ALMEIDA, Op. Cit., p. 188.

${ }^{6}$ Ibidem, p. 190.
} 
dos direitos do homem, o qual reflete no direito à vida e ao bem-estar físico, finalizando na qualidade de vida.

Segundo a concepção de Bedin, a luta pelo direito ao meio ambiente sadio "visa garantir um meio ambiente saudável e equilibrado, sendo reivindicado pelos setores da população que estão preocupados com o futuro do planeta e com a qualidade de vida que vai se legar para às próximas gerações"7 . Esse acesso ao meio ambiente saudável e ecologicamente equilibrado é um direito inerente ao homem, não cabendo outro indivíduo tirar-lo.

Logo o direito subjetivo ao meio ambiente ecologicamente equilibrado não se fundamenta exclusivamente na dignidade da pessoa humana, mas em toda uma gama de princípios fundamentais. Porém, a dignidade representa o seu mais forte apelo, visto que traz consigo a consubstanciação de todos os conteúdos que tornam possíveis os discursos de direitos fundamentais consolidados através do tempo. Corroborando, Del'Olmo retrata que

o direito a um meio ambiente ecologicamente equilibrado está diretamente relacionado ao direito à vida, o direito base de todos os demais, já que é essencial para se desfrutar de uma vida digna, sadia e com qualidade. Por essa razão, um ambiente ecologicamente equilibrado também é considerado um direito fundamental ${ }^{8}$.

Os indivíduos tem titularidade em relação ao meio ambiente, no entanto, o direito ao meio ambiente saudável coloca-se como um direito difuso, ou seja, é um direito para toda sociedade. Nesse sentido, não se trata portanto apenas de um bem onde o indivíduo irá se apropriar. Não obstante a isso, a proteção ambiental tem sido crescentemente reconhecida no direito internacional e nacional, onde cada área continua seguindo o caminho de seu próprio regime, entretanto, tanto a legislação dos direitos humanos como a legislação ambiental voltamse para a preocupação do bem-estar coletivo.

Não obstante a isso, os direitos humanos passaram por uma longa evolução histórica com possível origem nos primórdios do Cristianismo, sendo previstos na Declaração Universal dos Direitos Humanos de 1948. O reconhecimento da proteção do meio ambiente e do direito ao meio ambiente como um direito humano, tem como marco importante a Declaração de Estocolmo de 1972, estabelecendo princípios alinhavados com a preservação do meio ambiente.

\footnotetext{
${ }^{7}$ BEDIN, Gilmar Antonio. Os Direitos do Homem e o Neoliberalismo. 2. ed. Ijuí: Unijuí, 1997. p. 80.

8 DEL'OLMO, Elisa Ceriolli. Meio Ambiente Ecologicamente Equilibrado: direito e dever do cidadão. In: SANTOS, André Leonardo Copetti; DEL'OMO, Florisbal de Souza (Orgs.) Diálogo e Entendimento: direito e multiculturalismo e cidadania e novas formas de solução de conflitos. Rio de Janeiro: Forense, 2009. p. 226.
} 
Mas essa separação das legislações a partir de uma perspectiva ecológica, não é em si um problema. 0 que efetivamente importa é a racionalidade em que cada uma se baseia, ou seja, o sistema de valores inerentes a cada indivíduo. Entretanto, o grau em que a superioridade presumida dos direitos humanos for usada determinará o grau de proteção ambiental.

Como bem dispõe Bosselmann, a

[...] racionalidade econômica dos direitos humanos favorece valores individuais e materiais em detrimento dos valores coletivos e imateriais. Uma racionalidade ecológica dos direitos humanos, por outro lado, não necessariamente inverteria essa ordem, mas questionaria seu utilitarismo subjacente. [...]. A relação entre os direitos humanos e o meio ambiente é determinada por sua racionalidade prevalecente, e não exatamente por raciocínio jurídico?

No mesmo sentido preconiza Bedin, quando se reconhece a liberdade para o mercado, “o neoliberalismo representa, seja como proposta teórica seja como experiência concreta, uma grande ameaça aos direitos do homem, em especial aos direitos econômicos e sociais" 10 . Para ele, todos os problemas do nosso tempo podem ser resumidos na luta pelo reconhecimento e pelo respeito aos direitos do homem.

A preocupação com a proteção dos direitos humanos e a preocupação com a proteção do meio ambiente se reforçam reciprocamente. Não resta dúvida de que, tanto os direitos humanos quanto a legislação ambiental são necessários para proporcionar melhores condições de vida para os seres humanos. No entanto, a proteção dos direitos individuais tem caminhado em direção à proteção ambiental - por exemplo, os direitos de propriedade não têm sido conducentes a alcançar a sustentabilidade ecológica.

O meio ambiente precisa ser visto como um bem esgotável e limitado, que uma vez degradado não mais se recupera, gerando assim, consequências catastróficas para esta mesma sociedade que prima pelo capitalismo e pelo consumo em detrimentos dos bens naturais. 0 desenvolvimento sustentável depende de uma transformação nas concepções de prioridades dos indivíduos, como também de uma (re)conscientização das relações dos homens com o meio ambiente, em que pese ainda, deve-se haver uma mudança drástica no processo de desenvolvimento econômico e social.

As exigências capitalistas caracterizadas pela voracidade global provocam a destruição do ambiente de modo a obrigar-lhe a uma reação. Nesse cenário, são cabíveis as lições de Bobbio, pois,

\footnotetext{
${ }^{9}$ BLOSSELMANN, KLAUS. Direitos Humanos, Meio Ambiente e Sustentabilidade. In: SARLET, Ingo Wolfgang (Org.). Estado Socioambiental e Direitos Fundamentais. Porto Alegre: Livraria do Advogado, 2010. p. 74. ${ }^{10}$ BEDIN, Op. Cit., p. 107.
} 
O problema grave do nosso tempo, com relação aos direitos do homem, não era mais o de fundamentá-los, e sim o de protegê-los. [...] Não se trata de saber quais e quantos são esses dirietos, [...] mas sim qual é o modo mais seguro de garantí-los para impedir que, apesar de solenes declarações, eles sejam continuamente violados ${ }^{11}$.

Certo é que já houve um grande avanço no que diz respeito às garantias ambientais, todavia a sociedade contemporânea consume de forma assustadora, onde permeia além do individualismo, a incompreensão da situação preucupante em que o planeta terra está inserido. Nesse quadro representa-se uma busca desenfreada pela satisfação dos desejos individuais, vindo assim a sugar do meio ambiente tudo aquilo que possa servir de instrumentos para satisfação dos seus objetivos sem se preocupar com as consequências - que por óbvio, já se refletem.

Para Silva, "essa cultura ocidental, que hoje busca uma melhor qualidade de vida, é a mesma que destruiu e ainda destrói o principal modo de obtê-la: a Natureza, patrimônio da Humanidade, e tudo o que pode ser obtido a partir dela, sem que esta seja degradada"12. 0 problema da tutela jurídica do meio ambiente manifesta-se a partir do momento em que sua degradação passa a ameaçar não só o bem-estar, mas a qualidade da vida humana, se não a própria sobrevivência do ser humano.

Boff faz uma constatação bastante nefasta da sociedade e das consequências dos atos por ela praticados: Diante disso

[...] fizemo-nos reféns de um modelo civilizatório depredador e consumista que, se universalizado, demandaria três planetas semelhantes ao nosso. [...] Evidentemente isso é impossível, o que comprova a falta completa de sustentabilidade de nosso modo de produção, distribuição e consumo de bens e serviços. Não são poucos os analistas do estado da Terra que advertem: ou mudamos de padrão de relacionamento com a Terra ou vamos ao encontro do pior $^{13}$.

É importante que se tenha consciência de que o direito à vida é como matriz de todos os direitos fundamentais do homem, em que a orientação alcance todas as formas de atuação no campo de tutela do meio ambiente. Esse é um fator preponderante que há de estar acima de

\footnotetext{
11 BOBBIO, Norberto. A Era dos Direitos. Tradução: Carlos Nelson Coutinho. 16 tir. Rio de Janeiro: Campus, 1992. p. 25.

${ }^{12}$ SILVA, José Afonso da. Direito Ambiental Constitucional. 7.ed. São Paulo: Malheiros, 2009. p. 25.

${ }^{13}$ BOFF, Leonardo. Ecologia e Espiritualidade. In: TRIGUEIRO, André (Org.). Meio Ambiente do Século 21. Rio de Janeiro: Sextante, 2003. p. 43.
} 
quaisquer outras considerações como as de desenvolvimento, as de respeito ao direito de propriedade e as de iniciativa privada.

O meio ambiente precisa ser encarado muito mais do que uma mera política pública. Há uma necessidade de um refletir e de um agir crítico na tentativa da preservação e proteção dos recursos ambientais - eles podem contribuir para o desenvolvimento social e econômico, sem que com isso sejam erradicados do planeta. O desenvolvimento sustentável tem que obrigatoriamente passar por um pacto entre a sociedade e o meio ambiente, onde esta possa atingir seus objetivos consumistas e capitalistas sem comprometer as futuras gerações.

Neste sentido, a crise ambiental que hora se faz presente, deixa claro uma consequência já esperada. Esse aspecto desenfreado de descuido ambiental necessita de uma revisão nos processos, cujos princípios estejam alinhavados com uma gestão política mais sustentável, com planejamentos viáveis, bem como sua exequibilidade.

Ainda Douzinas leciona que o

[...] reconhecimento mútuo dos cidadãos como agentes autodeterminantes decorre da livre participação no processo democrático de tomada de decisões e da sua ampliação da política para outras áreas da vida social. 0 autodesenvolvimento, por outro lado, é o oposto da opressão: ele requer a ampliação do princípio da igualdade, da tomada de decisão jurídica para um número cada vez maior de áreas da vida social, tais como o local de trabalho, a vida doméstica, o meio ambiente etc., e sua transformação de um princípio formal para um substantivo ${ }^{14}$.

Esse panorama de constante ameaça da coletividade face a busca descomedida pela satisfação dos desejos pessoais, induz de acordo com Leite e Ayala ${ }^{15}$, a uma sociedade de risco. No entanto, na medida em que houver a interferência no meio ambiente, ocasionará um perigo para sociedade, onde os reflexos serão muitas vezes irreversíveis. O individualismo torna temerário não só o direito a um meio ambiente equilibrado, como todos os demais direitos abarcados pelos direitos humanos. A sociedade contemporânea não tem limites para atingir seus objetivos egoístas e egocêntricos, ao contrário, ela é orientada pela sedução, por desejos sempre crescentes e quereres voláteis.

\footnotetext{
${ }^{14}$ DOUZINAS, Costas. O Fim dos Direitos Humanos. Traduzido por Luiza Araújo. São Leopoldo: Unisinos, 2009. p. 294.

${ }^{15}$ LEITE, José Rubens Morato; AYALA. Patrick de Araújo. Direito Ambiental na Sociedade de Risco. Rio de Janeiro: Forense Universitária, 2002.
} 
Parte-se do princípio que a própria sustentabilidade deve ser entendida como uma solução ainda desconhecida em última análise, contudo o meio ambiente é complexo e possui uma diversidade de componentes, ou seja, não engloba apenas o verde e não implica uma vedação ao progresso, ao avanço industrial, mas ao desenvolvimento sustentável que compatibilize desenvolvimento econômico e proteção ao meio ambiente. Os problemas estão relacionados ao cotidiano e interferem diretamente na qualidade de vida.

Ainda em questão, o direito ao meio ambiente saudável e ecologicamente equilibrado na condição de direito, é de titularidade de toda pessoa humana. Sua efetividade depende de ética ambiental, a qual lastreada no cuidado deve-se guardar relações com a ciência da ecologia, de modo que o conhecimento do saber ecológico possibilite a consciência da fragilidade da vida. Os próprios indivíduos e o Estado são atores principais na garantia da efetividade de tais direitos. Necessária se faz outra forma de postura de cada indivíduo diante do meio, como também, necessária é uma efetiva política de gestão ambiental.

\section{JUSTIÇA AMBIENTAL E O CIDADÃO: A SUSTENTABILIDADE INDISSOCIÁVEL DA DEMOCRACIA E DO HUMANISMO}

Para que ocorra a concretização de um Estado de Direito Ambiental exigem-se mudanças radicais na estrutura existente da sociedade organizada. Além da conscientização global da crise ambiental, se torna imprescindível implantar uma ostensiva cidadania participativa em que haja a ação conjunta do Estado e da coletividade. O objetivo comum da cidadania ambiental deve ser a proteção intercomunitária do bem difuso ambiental, que é objeto de relevância comum a todos.

No entanto, a referida mudança exige atuação fundamental do Estado na proteção ambiental por uma política ambiental já nas pequenas comunidades, sendo difundida a tarefa de colaborar com ações que visem a proteção ambiental, sendo que os indivíduos dessas comuniddes, conhecedoras dos benefícios que essas ações trazem em prol da humanidade. A introdução da visão democrática ambiental leva a uma gestão participativa no Estado, que estimulará o exercício da cidadania com vistas ao gerenciamento da problemática ambiental.

Segundo a visão de Morais, uma das expressões mais evidentes dos interesses difusos é sem dúvida, aquela que diz respeito à questão ambiental, a qual se encontra agregada à questão social. Diante das possibilidades de extinção massiva da espécie humana e do esgotamento de 
recursos naturais, entre outros fatores, se faz necessário a incorporação de um novo conjunto de preocupações e uma transformação radical nas práticas jurídico-político-sociais ${ }^{16}$. No entanto,

\begin{abstract}
A questão ambiental pôs em pauta não apenas a necessidade de se pensar estratégias novas de tratamento jurídico-político, como trouxe para o universo de preocupações jurídico-econômico-políticas o asseguramento das condições de vida - com qualidade - para as futuras gerações, uma vez explícita a sua inapropriabilidade exclusivista - própria aos interesses individuais - e tão só contemporânea - ou seja, do tempo presente - por, como diria Mauro Cappelletti, dizer respeito a todos e ninguém ao mesmo tempo, sendo todos incluindo os das presentes e os das futuras gerações - forjando o que se nomeia como compromisso intergeracional ${ }^{17}$.
\end{abstract}

É notável que as gerações futuras apresentam-se como um novo ator interessado. Entretanto, pode-se então dizer que a questão ambiental tem como interessados gerações atuais e futuras, impondo com isso um conjunto de preocupações. Como bem mencionado, o dilema ambiental ultrapassa em muito a lógica estruturante do Estado Moderno e de seu direito, onde entretanto, acaba sendo submetido aos estritos limites de sua territorialidade e de suas fórmulas sancionatórias. Esse novo paradigma exige muito mais que puras normas consensuadas de proteção à natureza, exige uma motivação para agir de acordo com o que é eticamente correto.

O quadro ambiental contemporâneo clama por uma mudança de consciência, ou seja, uma reforma jurídica juntamente com uma reforma social, mesmo assim ainda será insuficiente sem uma mudança radical na maneira como encaramos nosso lugar na natureza. Destacando os direitos humanos como protetor das necessidades humanas de integridade ambiental, é imprescindível que se faça uma redefinição das responsabilidades humanas em relação à natureza. "O direito e apelos por uma nova moralidade não podem existir e de fato não existem em vácuos, e tampouco podemos esperar que eles nos oferecessem soluções para nossos mais profundos e complexos problemas ${ }^{18 "}$.

As circunstâncias apontam que a questão ambiental tem uma dimensão global, pois, com o desrespeito ou negligência por parte dos indivíduos, onde tomaram-se forma muito rapidamente as consequências na natureza, que por sua vez, geram efeitos de diferentes gravidades para toda huanidade. As possibilidades de tratamento local e nacional dos incidentes

\footnotetext{
${ }^{16}$ MORAIS, José Luis Bolzan de. Do Estado Social das "Carências" ao Estado Social dos "Riscos". Ou: de como a questão ambiental especula por uma nova cultura jurídico-política. Caderno de Direito Constitucional, 2008. Disponível em: < http:// www.trf4.jus.br/trf4/upload/editor/apg_ BOLZAN_ COMPLETO.pdf>. Acesso em: 15 set 13.

${ }^{17}$ Ibidem, p. 67.

${ }^{18}$ BOSSELMANN, Op. Cit., p. 96.
} 
ambientais estão afetadas, uma vez que, o Estado Nacional se mostra limitado. 0 meio ambiente encarado como uma realidade global impondo um tratamento inovador, o que repercute também sobre a perspectiva das políticas e práticas do Estado e para além do Estado.

Bolzan ainda lembra que,

[...] que o dilema ambiental impõe à interrogação não só os limites possíveis do Estado, como forma institucional da modernidade, como também a todos os instrumentos até então postos à disposição da regulação jurídica do meio ambiente e de sua afetação. [...] para darmos conta da questão ambiental tomada como um interesse cujas dimensões se agigantam tanto subjetivamente (envolvem interesses difusos) como espacialmente (territorialmente), bem como geracionalmente (envolvem interesses intergeracionais), mister se faz que não fiquemos presos aos esquemas conceituais e institucionais da modernidade tanto quanto aos mecanismos regulatórios utilizados pelo Direito Moderno [... $]^{19}$.

Dessa forma a questão ambiental não se sujeita aos limites territoriais da ordem jurídica moderna e suas estratégias. Segundo Menuzzi e Caron, as normas de preservação do meio ambiente são necessárias porém, não consegue orientar os comportamentos, que é uma questão de ética. "A crise ecológica necessita antes de mais nada de ética, porque se trata de um cambio paradigmático no modo de encarar a natureza. A pura resposta jurídica não resolverá os problemas ambientais"20.

O meio justo depende de um debate democrático, o qual agora enfrenta a urgência de desafios inéditos, entre eles, as atitudes passíveis de modificar a nossa forma de habitar a Terra. Contudo, para que se tome um novo rumo à questão ambiental é preciso que se opere uma profunda transformação no modo de vida contemporâneo, onde uma opção seja o Estado, a sociedade, a ciência e a economia capitalista. A questão ambiental implica em um novo arranjo social que provavelmente não dispensará nenhum dos âmbitos possíveis de tratamento, o local, o nacional, o supranacional, o mundial; o espaço público estatal, o espaço público não-estatal, e o espaço privado, que entretanto exigirá um conserto social que se constitua a partir de práticas e vínculos construídos sobre instrumentos de uma democracia sustentável ${ }^{21}$.

0 que interliga o direito ao meio ambiente ecologicamente equilibrado à temática social é a proteção do meio ambiente, que tem o papel de ater-se a uma problemática sensível

${ }^{19}$ MORAIS, Op. Cit., p. 69-70.

${ }^{20}$ MENUZZI, Jean Mauro; CARON, Braulio Otomar. Paradigma Ecológico e Fundamentação de Direito Ambiental. In: SANTOS, André Leonardo Copetti; DEL'OMO, Florisbal de Souza (Orgs.). Diálogo e Entendimento: direito e multiculturalismo e cidadania e novas formas de solução de conflitos. Rio de Janeiro: Forense, 2009. p. 221.

${ }^{21}$ MORAIS, Op. Cit. 
da questão do desenvolvimento capitalista, bem como, propor debate referente ao meio ambiente na frente a sociedade. Ainda nesse sentido, a inserção de toda e qualquer política pública ambiental deverá preocupar-se, a partir da ética com a questão social por detrás envolvida.

O mesmo se dá com relação à cidadania ambiental, pois, para que as disposições da cidadania ambiental se concretizem, necessária se faz "a participação do cidadão por meio do exercício da cidadania e a ampla consciência individual e coletiva da necessidade permanente da proteção contínua e sistemática da natureza como condição de qualidade de vida e da própria sobrevivência humana"22.

Portanto, para que se possa usufruir plenamente o direito fundamental a um ambiente saudável, imperioso é o cumprimento do dever fundamental de defesa do meio ambiente. 0 direito ao meio ambiente sadio e o dever de preservá-lo são conexos, uma vez que não é possível usufruir o meio ambiente ecologicamente equilibrado na medida em que se olvida a obrigação jurídico-ética de colaborar para sua preservação.

Contudo, a coletividade onde governos, indústrias, ciência e população estão alicerçadas em uma dimensão participativa e social, tem o direito mas também o dever à manutenção da vida com qualidade. Mais que isso, tem a responsabilidade de preservar o meio ambiente para que se possa viver um vida digna no ambiente em que se está inserido.

\section{CONCLUSÃO}

$\mathrm{Na}$ origem da sustentabilidade para espécie humana, para poder compreender realmente o problema ambiental propriamente dito, são necessários suportes onde prevaleçam valores intrínsecos dos seres humanos. Contudo, um dos indicadores em relação a humanidade para com a natureza, dá-se por meio desenvolvimento sustentável, que extrai do meio ambiente o que é necessário para sobreviver.

No tocante ao interesse do mercado, o fio condutor central referente ao crescimento desordenado da economia revela que os cidadãos podem diminuir eventuais ações impactantes ao ecossistema que as sustentam, garantindo uma melhor qualidade de vida. No que se refere ao preço que cada indivíduo paga para ter um ambiente sustentável, não caberá discussão, uma vez que, não tem valor equivalente.

${ }^{22}$ Del’Omo, Op. Cit., p. 233. 
No tocante a gestão ambiental que é a questão central para o desenvolvimento sustentável, estabelecer um desejo comum das estratégias com que ela contribua configura um problema da gestão ambiental sustentado pela deficiência na aplicabilidade, onde as legislações não estão conseguindo cumprir sua finalidade. No entanto, os estabelecimentos de instâncias permanentes de participação popular para a aplicação de recursos públicos e a formulação de políticas públicas, constituem-se em importantes caminhos para aprofundar os valores democráticos, sociais e humanistas. A sustentabilidade necessita desses valores para que de fato tome um impulsão para atender todos os seres humanos.

O reconhecimento do direito ao meio ambiente sadio como um dos direitos fundamentais da pessoa humana, decorre da urgência em construir uma sociedade que tenha como base a democracia, participação e a solidariedade. Também não bastam legislações positivas garantidoras, pois não são suficientes, sendo necessária a conscientização da sociedade de que somos agentes sujeitos capazes em interação no planeta, naquilo que fazemos e naquilo que deixarmos de fazer, em aspectos positivos ou negativos, definindo a qualidade ambiental e por consequência, qualidade de vida. Para se levar a cabo esses objetos que foram identificados como peças chaves, devem ser tomadas medidas que sensibilizem a sociedade, com o convencimento de que não são apenas problemas dos órgãos fiscalizadores competentes, pois nesse ambiente, todos estão inseridos e mais do que tudo, dependem para sobreviver e perpetuar.

\section{REFERÊNCIAS}

BEDIN, Gilmar Antonio. Os Direitos do Homem e o Neoliberalismo. 2. ed. Ijuí: Unijuí, 1997.

BLOSSELMANN, KLAUS. Direitos Humanos, Meio Ambiente e Sustentabilidade. In: SARLET, Ingo Wolfgang (Org.). Estado Socioambiental e Direitos Fundamentais. Porto Alegre: Livraria do Advogado, 2010.

BOBBIO, Norberto. A Era dos Direitos. Tradução: Carlos Nelson Coutinho. 16 tir. Rio de Janeiro: Campus, 1992.

BOFF, Leonardo. Ecologia e Espiritualidade. In: TRIGUEIRO, André (Org.). Meio Ambiente do Século 21. Rio de Janeiro: Sextante, 2003.

CENCI, Daniel Rubens. O Direito ao Meio Ambiente Ecologicamente Equilibrado como Direito Fundamental da Pessoa Humana. In: BEDIN, Gilmar Antonio (Org.). Cidadania, Direitos Humanos e Equidade. Ijui: Unijuí: 2012.

DEL'OLMO, Elisa Ceriolli. Meio Ambiente Ecologicamente Equilibrado: direito e dever do cidadão. In: SANTOS, André Leonardo Copetti; DEL’OMO, Florisbal de Souza (Orgs.) Diálogo e 
Entendimento: direito e multiculturalismo e cidadania e novas formas de solução de conflitos. Rio de Janeiro: Forense, 2009.

DOUZINAS, Costas. O Fim dos Direitos Humanos. Traduzido por Luiza Araújo. São Leopoldo: Unisinos, 2009.

LEITE, José Rubens Morato; AYALA. Patrick de Araújo. Direito Ambiental na Sociedade de Risco. Rio de Janeiro: Forense Universitária, 2002.

MENEGAT, Rualdo. Ciência Cidadã: democracia, e territorialidade por uma epistemologia urbana. In: MENEGAT, Rualdo; ALMEIDA, Gerson (Orgs.). Desenvolvimento Sustentável e Gestão Ambiental nas Cidades - Estratégias a partir de Porto Alegre. Porto Alegre: Editora da UFRGS, 2004.

MENEGAT, Rualdo; ALMEIDA, Gerson. Sustentabilidade, Democracia e Gestão Ambiental Urbana. In: MENEGAT, Rualdo; ALMEIDA, Gerson (Orgs.). Desenvolvimento Sustentável e Gestão Ambiental nas Cidades - Estratégias a partir de Porto Alegre. Porto Alegre: Editora da UFRGS, 2004.

MENUZZI, Jean Mauro; CARON, Braulio Otomar. Paradigma Ecológico e Fundamentação de Direito Ambiental. In: SANTOS, André Leonardo Copetti; DEL'OMO, Florisbal de Souza (Orgs.). Diálogo e Entendimento: direito e multiculturalismo e cidadania e novas formas de solução de conflitos. Rio de Janeiro: Forense, 2009.

MORAIS, José Luis Bolzan de. Do Estado Social das "Carências" ao Estado Social dos "Riscos". Ou: de como a questão ambiental especula por uma nova cultura jurídico-política. Caderno de Direito Constitucional, 2008. Disponível em: <

http://www.trf4.jus.br/trf4/upload/editor/apg_BOLZAN_COMPLETO.pdf >. Acesso em: $1^{\circ}$ Mai. 2014.

SILVA, José Afonso da. Direito Ambiental Constitucional. 7.ed. São Paulo: Malheiros, 2009.

Recebido em: 01.10.2013

Revisões em: 14.04.2014

Aprovado em: 04.06.2014 